\title{
First report of Grapevine Pinot gris virus infecting grapevine in Brazil
}

\author{
Thor Vinícius Martins Fajardo ${ }^{1} \cdot$ Marcelo Eiras $^{2} \cdot$ Osmar Nickel $^{1}$
}

Received: 15 May 2017 / Accepted: 18 August 2017

(C) Australasian Plant Pathology Society Inc. 2017

\begin{abstract}
Grapevine Pinot gris virus (GPGV) has been reported infecting grapevines (Vitis spp.) in several countries of the world. In this study, 19.5\% of grapevine samples collected in Brazil and indexed for GPGV by RT-qPCR was infected. The complete coat protein and the partial replicase genes of two Brazilian isolates (CF-BR and ME-BR) were sequenced and exhibited very high nucleotide and deduced amino acid identities with many foreign characterized isolates of GPGV available in the GenBank. This is the first detection of GPGV infecting grapevines in Brazil.
\end{abstract}

Keywords GPGV $\cdot$ Trichovirus $\cdot$ RT-qPCR $\cdot$ Real time RT-PCR · Diagnosis

Among grapevine (Vitis spp.) pathogens, viruses stand out, since this crop is infected by many graft-transmissible agents that cause several diseases, reducing plant vigor, yield, productivity and also fruit quality. In this context, the knowledge of the identity of viruses that infect grapevines in a specific viticultural region is important, constituting an essential requirement for the development of more accurated detection methods and also to implement virus management or control measures (Basso et al. 2017).

Symptoms of chlorotic mottling and leaf deformation were reported for the first time in grapevines $(V$. vinifera) $\mathrm{cv}$. Pinot Gris in Italy in 2003, with which a novel virus, Grapevine

Thor Vinícius Martins Fajardo

thor.fajardo@embrapa.br

1 Embrapa Uva e Vinho, Rua Livramento, 515, Bento Gonçalves, RS 95701-008, Brazil

2 Instituto Biológico, Av. Conselheiro Rodrigues Alves, 1252, São Paulo, SP 04014-002, Brazil
Pinot gris virus (GPGV), was associated (Giampetruzzi et al. 2012). The virus has been reported infecting several varieties in many European countries (Czech Republic, France, Germany, Greece, Portugal, Slovakia, Slovenia, Spain and Turkey), as well as in Australia, Canada, China, Korea and USA (Glasa et al. 2014; Saldarelli et al. 2015; Bertazzon et al. 2016a; Eichmeier et al. 2016a; Wu and Habili 2017). Its association with the disease is still not completely established, due to the existence of different viral strains and diverse cultivar's susceptibility (Saldarelli et al. 2015). However, the associated disease has an important economic impact since it affects plant vigor and reduces yield. The eriophyid mite Colomerus vitis is a vector of GPGV (Malagnini et al. 2016) and the herbaceous plants Silene latifolia subsp. alba and Chenopodium album can be considered as reservoirs of the GPGV (Gualandri et al. 2017). GPGV is a member of the genus Trichovirus, family Betaflexiviridae, and possesses a ssRNA with 7275 nucleotides (Giampetruzzi et al. 2012).

No information about the incidence, prevalence and variability of GPGV strains in Brazilian grapevines is hitherto available. Therefore, the aim of this work was to determine the prevalence of GPGV infecting Brazilian grapevines and perform a molecular characterization of coat protein $(\mathrm{CP})$ genes of this viral species.

Eighty grapevine cuttings from nurseries of many viticultural countries, imported between 2000 and 2004 and since then maintained in a collection under greenhouse conditions at Embrapa Grape and Wine were sampled for indexing. These plants of many cultivars exhibited non-virus-specific symptoms or were asymptomatic. Other 46 grapevine samples (cvs Cabernet Franc, Chardonnay, Pinot Noir, Merlot and Riesling Italico) from recently (2015) imported cuttings were also tested. Finally, 172 grapevine samples collected from many cultivars and genotypes (V. vinifera and V. labrusca) in 
germplasm and grapevine collections of Brazilian research institutions from several States (Pernambuco, Minas Gerais, São Paulo, Paraná, Santa Catarina and Rio Grande do Sul) were also evaluated, totalizing 298 samples from three sources. The mother vines of this last block of samples have been independently introduced in Brazil from many countries within the last ca. 25 years.

Total RNA extractions from $1 \mathrm{~g}$ of scrapings of mature stems were performed using the adsorption of nucleic acids on silica particles (Rott and Jelkmann 2001), grinding plant tissues in liquid nitrogen. Appropriated controls were included in all performed analyses. RT-qPCR reactions were carried out using the kit TaqMan ${ }^{\circledR}$ Fast Virus 1-Step Master Mix (Life Technologies) in a thermocycler StepOnePlus Real-time PCR System (Applied Biosystems) as previously described (Fajardo et al. 2016). Reaction data were analyzed using the StepOne Software v.2.3 (Applied Biosystems) by determining the $\mathrm{Ct}$ (threshold cycle). Two sets of primer pairs and probes used for GPGV detections by RT-qPCR were previously designed by Bianchi et al. (2015), GPgVPozRT-F, GPgVPozRT$\mathrm{R}$ and GPgVPozRT probe (amplify $104 \mathrm{bp}$ in the RNA dependent RNA polymerase region of GPGV) and GPgV504F, GPgV588R and GPgV CP542 probe (amplify 85 bp in the CP gene). The probes were labeled with 6-FAM and TAMRA in the $5^{\prime}$ and $3^{\prime}$ ends, respectively.

$\mathbf{a}$

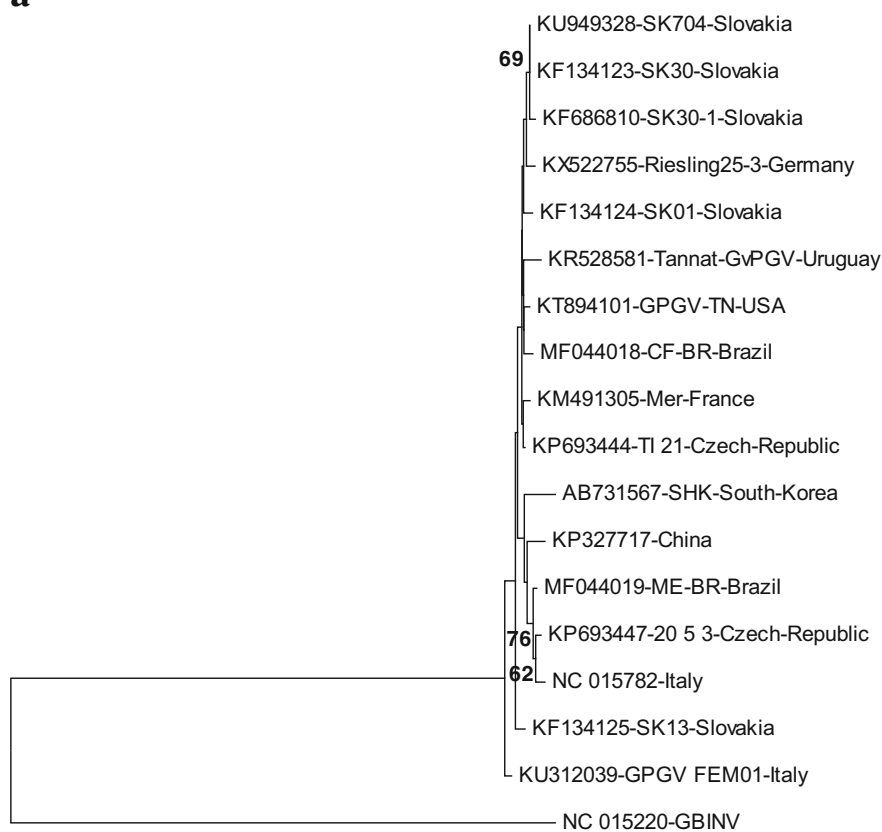

$\longmapsto 0.05$

Fig. 1 Phylogenetic relationship among GPGV isolates based on the multiple alignment of (a) nucleotides and (b) deduced amino acids of the complete coat protein genes of two Brazilian isolates and other 15 isolates available in the GenBank. The tree was constructed by the Neighbor-joining method using MEGA 7, and bootstrapped with 2000
Complementary DNA synthesis was performed using $1 \mu \mathrm{L}$ hexanucleotides (random primers) at $10 \mu \mathrm{M}$ in reactions using reverse transcriptase (Ludwig Biotecnologia) at $50{ }^{\circ} \mathrm{C}$ for $1 \mathrm{~h}$ and $4 \mu \mathrm{L}$ of total RNA (ca. $400 \mathrm{ng}$ ) as defined by the manufacturer. Two sets of primer pairs were used to amplify the complete CP of GPGV, DetF (Saldarelli et al. 2015) and GPgV588R (Bianchi et al. 2015), and the partial RNA dependent RNA polymerase (RdRp) domain of the GPGV replicase gene, GPGVRepF and GPGVRepR (Saldarelli et al. 2015). Amplification cycling, cloning and purification of recombinant plasmids from Escherichia coli were performed as described by Fajardo et al. (2016). Automatic nucleotide sequencing was performed with two clones per amplicon and isolate.

The nucleotide (nt) and deduced amino acid (daa) identities among the two Brazilian isolates and 15 isolates of GPGV from GenBank were determined using BioEdit v.7.2.5 software. Multiple sequence alignments were performed using ClustalX 2.1 program (Larkin et al. 2007). Nucleotide and deduced amino acid phylogenetic relationships were determined using Neighbor-joining method implemented in MEGA 7 program using Kimura 2-parameter with gamma distribution $(\mathrm{G})$ and bootstrap support from 2000 replications (Kumar et al. 2016), and phylogeny reconstruction and pdistance substitution model, respectively.

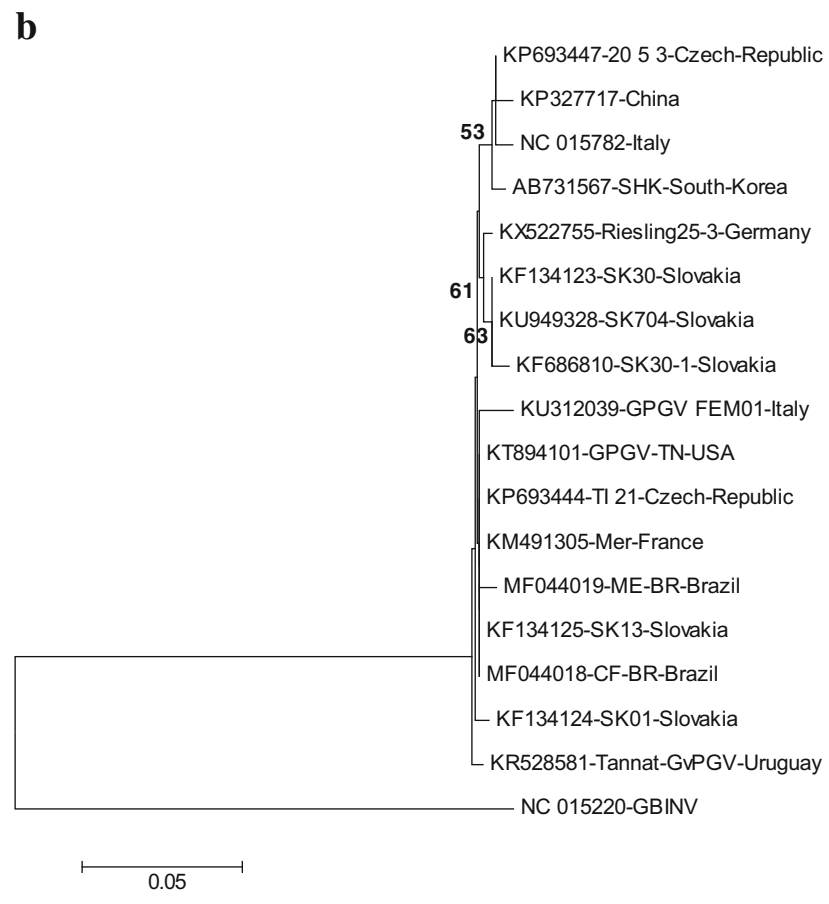

replications. Bootstrap values ( $>50)$ are reported at the nodes. Names of GPGV isolates and origins were included according to the GenBank. Grapevine berry inner necrosis virus (GBINV), a Trichovirus, was used as outgroup. Bar: number of substitutions per site 
The first report of GPGV in Brazil, while it adds knowledge to the phytosanitary status of a defined viticultural region, is also important to give support to management and control measures of grapevine diseases. Accordingly, 298 grapevine samples, assayed by RT-qPCR, revealed an impressive mean infection rate (58 samples, 19.5\%). Considering the source of samples individually, the GPGV incidence in the oldest imported grapevine cutting block was 3 out of 80 indexed samples (3.8\%); 36 GPGV-infected samples out of 46 in the more recent imported grapevine cutting block $(78.3 \%)$ and, finally, 19 GPGV-infected samples out of $172(11.1 \%)$ in grapevine accessions from Brazilian germplasm and grapevine collections. This result is especially interesting considering the different geographical origins and a wide range of grapevine genotypes that include commercial cultivars of wine and table grapevines.

Considering the restricted number of plants analyzed in this work, the findings suggest the likely widespread occurrence of GPGV in Brazilian vineyards. The sudden emergence of GPGV in a number of different countries suggests a longer presence of the virus in those viticultural regions where it had persisted unnoticed, although symptoms of leaf mottling and deformations have already been reported for example in cv. Chardonnay (Eichmeier et al. 2016b). Also, Bertazzon et al. (2016b) showed that there was an important association between GPGV variants and symptom expression, and that grapevines with symptoms harboured a significantly higher GPGV titre than symptomless vines. In the present study, it was not possible to associate specific symptoms with GPGV infections due to the frequent presence of multiple viral infections in the analyzed grapevines.

According to the requirements of production of plant propagation material of many viticultural countries, especially European Union, USA and South Africa, grapevine has to be tested for some viruses [Grapevine fanleaf virus (GFLV), Arabis mosaic virus (ArMV), Grapevine leafroll-associated virus 1 and 3 (GLRaV-1 and -3) as well as for Grapevine fleck virus (GFkV) in the case of rootstock mother plants] (Audeguin 2012). However, indexing of GPGV is not included as mandatory in the mentioned legislations. Besides this, some of the tested cuttings were imported before the establishment of such legal frameworks in their countries of origin. A lower incidence would have meant that, in fact, GPGV is a controlled pathogen, under regulation in imported cuttings. As already addressed (Eichmeier et al. 2016b), grapevine clones affected with viruses recognized as detrimental have been removed during many years of sanitary selections during the production process of grapevine propagation material (Basso et al. 2017). As a matter of fact, it seems that GPGV is one of the prevalent viruses infecting grapevine worldwide, widely distributed in many grape- growing areas of the world, being even considered as an emergent virus (Bertazzon et al. 2016a). Since many viruses are transmitted by vectors (e.g. mites for GPGV), new vineyards should be established with virus-free propagative materials to counteract disease spread.

A GPGV-specific DNA amplicon of 953 bp was amplified using the DetF/GPgV588R primer pair by RT-PCR from two grapevine (V. vinifera) samples, cvs. Cabernet Franc and Merlot, randomly selected among 58 GPGVinfected samples after indexing by RT-qPCR. Two complete nucleotide sequences of the GPGV coat protein (CP) genes (588 nt and 195 daa) were obtained from GPGV isolates CF-BR and ME-BR and deposited in GenBank under accession numbers MF044018 and MF044019. The multiple CP nucleotide and deduced amino acid sequence comparisons of two Brazilian isolates and other 15 foreign isolates of GPGV available in GenBank showed identities ranging from $96.9 \%$ to $99.3 \%$ and from $97.4 \%$ to $100 \%$, respectively, suggesting a limited CP gene variability of this virus species. The phylogenetic tree indicated that, although the analyzed sequences of GPGV isolates were unique to each variety (Cabernet Franc and Merlot), they were grouped within a single large clade indicating that GPGV is quite homogeneous when considering the CP genes of the studied isolates (Fig. 1a). This is confirmed by the amino acid sequence analysis from the same CP genes of GPGV (Fig. 1b). The nt and daa identities of CP gene between the CF-BR and ME-BR isolates were $98.2 \%$ and $99.4 \%$, respectively.

Another DNA amplicon of 525 bp was amplified using the GPGVRepF/GPGVRepR primer pair by RT-PCR from GPGV isolates CF-BR and ME-BR. These partial RdRp sequences were deposited in GenBank under accession numbers KY886452 and KY886453 and exhibited highest nt identities (98-99\%) with six homologous GPGV isolates available in Genbank (KX522755, KF134125, KP693445, KU312039, KU194413 and KM491305) and highest daa identities (98$100 \%$ ) with five homologous GPGV isolates (AOG16120, AIY29054, ANQ87152, AGV76027 and AKP16328), considering 175 daa translated from the sequenced DNA fragment.

The occurrence of GPGV was demonstrated for the first time in Brazil. The Brazilian characterized GPGV isolates showed a low genetic variability. Further studies should be performed to comprehensively characterize the incidence and the prevalence of this pathogen in the Brazilian commercial vineyards.

Acknowledgements To Embrapa for the financial support to this research (Project 02.13.14.002), Marcos F. Vanni (Embrapa) and Aléxis C. Kin (UERGS) for technical support. ME and ACK are supported by a $\mathrm{CNPq}$ research fellowship and by a FAPERGS student scholarship, respectively. 


\section{References}

Audeguin L (2012) French regulation, registration and certification: procedures, controls and perspectives. Proceedings of the $17^{\text {th }}$ congress of ICVG. Davis, California, pp 258-259

Basso MF, Fajardo TVM, Saldarelli P (2017) Grapevine virus diseases: economic impact and current advances in viral prospection and management. Rev Bras Frutic 39:e-411. https://doi.org/10.1590/ 0100-29452017411

Bertazzon N, Filippin L, Forte V, Angelini E (2016a) Grapevine Pinot gris virus seems to have recently been introduced to vineyards in Veneto, Italy. Arch Virol 161:711-714

Bertazzon N, Forte V, Filippin L, Causin R, Maixner M, Angelini E (2016b) Association between genetic variability and titre of Grapevine Pinot gris virus with disease symptoms. Plant Pathol. https://oi.org/10.1111/ppa.12639

Bianchi GL, de Amicis F, de Sabbata L, di Bernardo N, Governatori G, Nonino F, Prete G, Marrazzo T, Versolatto S, Frausin C (2015) Occurrence of Grapevine Pinot gris virus in Friuli Venezia Giulia (Italy): field monitoring and virus quantification by real-time RTPCR. EPPO Bulletin 45:22-32

Eichmeier A, Penázová E, Pavelková R, Mynarzová Z, Saldarelli P (2016a) Detection of Grapevine Pinot gris virus in certified grapevine stocks in Moravia, Czech Republic. J Plant Pathol 98:155-157

Eichmeier A, Komínková M, Komínek P, Baránek M (2016b) Comprehensive virus detection using next generation sequencing in grapevine vascular tissues of plants obtained from the wine regions of Bohemia and Moravia (Czech Republic). PLoS One 11:e0167966. https://doi.org/10.1371/journal.pone. 0167966

Fajardo TVM, Eiras M, Nickel O (2016) Detection and molecular characterization of Grapevine yellow speckle viroid 1 isolates infecting grapevines in Brazil. Trop Plant Pathol 41:246-253
Giampetruzzi A, Roumi V, Roberto R, Malossini U, Yoshikawa N, La Notte P, Terlizzi F, Credi R, Saldarelli P (2012) A new grapevine virus discovered by deep sequencing of virus- and viroid-derived small RNAs in cv. Pinot gris. Virus Res 163:262-268

Glasa M, Predajna L, Komínek P, Nagyová A, Candresse T, Olmos A (2014) Molecular characterization of divergent Grapevine Pinot gris virus isolates and their detection in Slovak and Czech grapevines. Arch Virol 159:2103-2107

Gualandri V, Asquini E, Bianchedi P, Covelli L, Brilli M, Malossini U, Bragagna P, Saldarelli P, Si-Ammour A (2017) Identification of herbaceous hosts of the Grapevine Pinot gris virus (GPGV). Eur J Plant Pathol 147:21-25

Kumar S, Stecher G, Tamura K (2016) MEGA7: molecular evolutionary genetics analysis version 7.0 for bigger datasets. Mol Biol Evol 33: 1870-1874

Larkin MA, Blackshields G, Brown NP, Chenna R, McGettigan PA, McWilliam H, Valentin F, Wallace IM, Wilm A, Lopez R, Thompson JD, Gibson TJ, Higgins DG (2007) Clustal W and Clustal X version 2.0. Bioinformatics 23:2947-2948

Malagnini V, de Lillo E, Saldarelli P, Beber R, Duso C, Raiola A, Zanotelli L, Valenzano D, Giampetruzzi A, Morelli M, Ratti C, Causin R, Gualandri V (2016) Transmission of Grapevine Pinot gris virus by Colomerus vitis (Acari: Eriophyidae) to grapevine. Arch Virol 161:2595-2599

Rott ME, Jelkmann W (2001) Characterization and detection of several filamentous viruses of cherry: adaptation of an alternative cloning method (DOP-PCR), and modification of an RNA extraction protocol. Eur J Plant Pathol 107:411-420

Saldarelli P, Giampetruzzi A, Morelli M, Malossini U, Pirolo C, Bianchedi P, Gualandri V (2015) Genetic variability of Grapevine Pinot gris virus and its association with grapevine leaf mottling and deformation. Phytopathology 105:555-563

Wu Q, Habili N (2017) The recent importation of Grapevine Pinot gris virus into Australia. Virus Genes. https://doi.org/10.1007/s11262$017-1475-6$ 